DOI: http://dx.doi.org/10.14393/che-v15n1-2016-15

\title{
Un análisis comparativo de las reformas educativas orgánicas de los años sesenta y noventa en Argentina. ¿Transformación o consolidación de tendencias?
}

\author{
A comparative analysis of organic educational reforms of the sixties and nineties in \\ Argentina. Transformation or trends consolidation?
}

Uma análise comparativa das reformas educativas orgânicas dos anos sesenta e noventa na Argentina. Transformação ou consolidação de tendencias?

\author{
ROMINA DE LUCA ${ }^{1}$ \\ NATALIA AlVAREZ PRIETO ${ }^{2}$
}

\section{Resumen:}

En el presente trabajo se analizan, comparativamente, dos momentos centrales de transformación educativa en Argentina: el proceso de reforma inaugurado por la Ley Orgánica de Educación (1968-1971) y la sanción de Ley Federal de Educación (1993). Ambos momentos dieron lugar a procesos de reforma orgánica que afectaron al conjunto de los niveles educativos y a la totalidad de los aspectos de la vida escolar (estructura del sistema, currículum, pautas de evaluación, normativa disciplinaria, etc.). A los efectos de dar cuenta de los objetivos propuestos, se examinan aquí distintas fuentes documentales: legislación, normativa educativa, documentos escolares e informes elaborados por organismos oficiales. A partir de su análisis, podrá observarse que la reforma llevada a cabo en los años sesenta buscaba consolidar una serie de tendencias que se venían desarrollando desde 1955, tales como la descentralización educativa y la regionalización curricular. Y si bien la reforma fue desarticulada prontamente, sus huellas permanecerían en los procesos de transformación educativa posteriores, como será el caso de la sanción de la Ley Federal en la década del noventa.

Palabras clave: Reforma de la educación, Argentina, Análisis Comparativo, Historia de la Educación

\footnotetext{
${ }^{1}$ Becaria Postdoctoral del Consejo Nacional de Investigaciones Científicas y Técnicas. Doctora en Historia por la Universidad de Buenos Aires. Contacto: ryrromina@yahoo.com.ar

${ }_{2}^{2}$ Becaria Doctoral del Consejo Nacional de Investigaciones Científicas y Técnicas. Licenciada en Sociología por la Universidad de Buenos Aires. Contacto: nataliaryr@hotmail.com
} 


\begin{abstract}
This article analyze, comparatively, two central moments of educational transformation in Argentina: the reform process inaugurated by the Organic Law of Education (1968-1971) and the enactment of Federal Law of Education (1993). Both inaugurated a process of organic reform that affected the overall educational levels and all aspects of school life (system structure, curriculum, evaluation standards, disciplinary rules, etc.). In order to realize the objectives proposed here, various documentary sources are examined: legislation, educational standards, school documents and reports by government agencies. Their analysis shows that the reform carried out in the sixties sought to consolidate a number of trends that had been developing since 1955, such as educational decentralization and regionalization curriculum. And while reform was disbanded soon, his footprints remain in the processes of educational change later, as is the case of the enactment of the Federal Law on the nineties.
\end{abstract}

Keywords: Educational reform, Argentina, Comparative analysis, History of Education

\title{
Resumo:
}

Neste trabalho são analisadas, comparativamente, dois momentos centrais de transformação educativa na Argentina: o processo de reforma inaugurado pela Lei Orgânica de Educação (1968-1971) e a promulgação da Lei Federal de Educação (1993). Ambos os momentos viabilizaram processos de reforma orgânica que afetaram os diferentes níveis educativos e a totalidade dos aspectos da vida escolar (estrutura do sistema, currículo, avaliação, normas disciplinares etc.). Com vistas a alcançar os objetivos propostos, examinam-se distintas fontes documentais: legislação, normas educacionais, documentos escolares e informes elaborados por organismos oficiais. A partir da análise destas fontes, pôde-se observar que a reforma levada a cabo nos anos sessenta buscava consolidar uma série de tendências que se desenvolviam desde 1955, tais como a descentralização educativa e a regionalização curricular. Mais, ainda que a reforma tenha sido desarticulada em pouco tempo, suas marcas permanecerão nos processos de transformação educativa posteriores, como foi o caso da promulgação da Lei Federal da década de noventa do Século XX.

Palavras-chave: Reforma da Educação, Argentina, Análise Comparativa, História da Educação. 


\section{Introducción}

Este artículo se propone analizar y comparar dos momentos de reforma educativa en Argentina. Por un lado, el proceso inaugurado por la Ley Orgánica de Educación (19681971), llevado a cabo por la dictadura militar autodenominada "Revolución Argentina". Por el otro, las transformaciones iniciadas a partir de la sanción de Ley Federal de Educación, en el año 1993, bajo el gobierno de Carlos Saúl Menem (1989-1999). La reforma de los años '60'70 ha sido poco estudiada por la historiografía local. Existen una serie de trabajos sobre los cambios en el currículum (Feldman y Palamidessi, 1994; Palamidessi, 2009) y la descentralización educativa (Paviglianitti, et al., 1989; Vior, 1999; Puiggrós, 2003). También han sido desarrollados una serie de estudios sobre algunos aspectos específicos de la reforma, entre los cuales se cuentan los referidos a la formación docente, los diagnósticos y sugerencias realizadas por organismos nacionales como el CONET y las transformaciones en el nivel universitario (Gamarnik, 1996; Davini, 1998; De Luca, 2006; De Luca y Southwell, 2009; De Luca y Alvarez Prieto, 2013). Por su parte, la reforma producida en la década del noventa dio lugar a una cuantiosa producción teórica. Las temáticas son diversas: descentralización, privatización, "retiro" del Estado, currículum, libros de texto, intervención de organismos internacionales en el diseño de las políticas educativas, etc. (Puiggrós, 2003b; Albergucci, 1996; Coraggio, 1997; Miranda y Lamfri, 2001; Ziegler, 2001; Echenique, 2003; Braslavsky et. al., 2001; Grinberg, 2005; Batiuk, 2006; Sanguinetti, 2006; Tiramonti, 2010). Sin embargo, ambos procesos han sido examinados en forma aislada, desatendiendo las similitudes existentes entre ellos. Así, por ejemplo, la estructura y organización curricular de los noventa parecieran ser originales de aquella década. En ese sentido, existe una mirada compartida que concibe esa reforma como el resultado de la instauración de un "Estado mínimo", producto de una ideología de tipo "neoliberal". Sin embargo, si se examina un período de tiempo más amplio, puede corroborarse que la transformación educativa de los noventa fue un momento de síntesis de tendencias con una larga trayectoria. Algunas de las cuales pueden encontrarse ya en la reforma de los años sesenta.

Si bien se ubican en contextos políticos diferentes (dictadura y democracia), los dos momentos que se analizan aquí dieron lugar a reformas "orgánicas" que afectaron al conjunto de los niveles educativos y a la totalidad de los aspectos de la vida escolar (estructura del sistema, currículum, pautas de evaluación, normativa disciplinaria, etc.). En este trabajo, se intentará dar cuenta de las características principales de esos procesos integrales de cambio, 
atendiendo algunos de sus distintos componentes. A partir de tal análisis, se podrá observar que ambos momentos buscaron consolidar una serie de tendencias que atraviesan, hasta hoy, al sistema educativo argentino. Fundamentalmente, la descentralización-regionalización, tanto a nivel normativo y estructural como curricular.

A los efectos de dar cuenta de los objetivos aquí propuestos, se emplearán diversas fuentes documentales: legislación y normativa educativa (leyes, decretos, resoluciones, reglamentos, circulares, etc.), informes elaborados por organismos oficiales y diseños curriculares, entre otras. Asimismo, para logar una mirada más cercana al impacto de estas reformas sobre la vida escolar, se trabajará con fuentes documentales obrantes en el archivo histórico de una importante escuela pública de nivel medio de la Ciudad Autónoma de Buenos Aires: la Escuela No 2 "Mariano Acosta".

\section{Las reformas}

\section{A. ¿Una experiencia fallida? Los años sesenta}

La reforma educativa de la década del sesenta tuvo lugar en el marco del golpe militar de 1966 encabezado por Juan Carlos Onganía a través de la autodenominada "Revolución Argentina" (1966-1973). Desde 1955, con el derrocamiento de Juan Domingo Perón, el país se encontraba atravesado por una crisis de hegemonía ${ }^{3}$ que daría lugar a sucesivos regímenes militares. El gobierno peronista, surgido a partir de un golpe de Estado en 1946, se enmarcaba en el contexto de un ascenso de la lucha de clases que ponía en cuestión al orden social capitalista en este país. En ese marco, Perón oficiaría como "árbitro" entre las clases sociales en disputa, incorporando algunas demandas secundarias de la clase obrera de manera de frenar su organización y lucha. De allí la alianza expresada por el peronismo entre el capital mercado-internista y las organizaciones sindicales obreras. De ese modo, se desarrollaba un proceso de características similares a los impulsados por Lázaro Cárdenas en México, dos décadas antes, y por Getúlio Vargas en Brasil, durante las décadas del `30 y `40. Ahora bien, tal alianza resultaba posible solo en el marco de una economía industrial en expansión, motorizada por las transferencias de renta agraria hacia el sector. Con la crisis económica de

\footnotetext{
${ }^{3}$ Entendemos por "hegemonía" la forma que adopta la dominación de la burguesía en las sociedades capitalistas en aquellos momentos en que no es desafiada abiertamente y aparece bajo formas "consensuales", si bien se asienta, en última instancia, en el uso o la amenaza de la violencia. Para ampliar el concepto, véase: Anderson, 1981; Sartelli, 1996.
} 
la década del cincuenta, y realizado ya el disciplinamiento de la clase obrera, la burguesía impulsará otra estrategia: terminar con esas transferencias y aumentar la productividad del capital (a partir de su concentración y centralización). Al carecer de una base política de masas para desarrollar esa estrategia, la burguesía apelará a los golpes de Estado. De allí el golpe de 1955 a manos de la "Revolución Libertadora" que pondrá fin a la experiencia peronista y que dará lugar a una crisis de hegemonía. Tal crisis suponía la imposibilidad, por parte de la burguesía argentina, de lograr articular una alianza en la que pudieran expresarse, al mismo tiempo, los intereses centrales de todas sus fracciones junto a los intereses secundarios de la clase obrera. Paulatinamente, en ese marco iría constituyéndose una fuerza social que, hacia fines de la década del sesenta, impugnaría con fuerza el orden social establecido. Ahora bien, ese proceso político se montaba sobre la base de una profunda crisis económica, con fases más o menos agudas, producto del agotamiento histórico del principal sostén de la economía argentina: la renta agraria. El golpe militar de 1966 sería la expresión de los sectores más concentrados del capital que buscarían quebrar la lógica agro-industria mercadointernista. Para ello, la dictadura impulsaría una intensa reestructuración de la economía argentina, asentada en un desarrollo en profundidad, eliminando a los capitales más débiles y expulsando mano de obra "sobrante" (Sartelli, 2006).

En ese contexto histórico, la reforma educativa ocuparía un lugar central dentro de los proyectos encarados durante la etapa. Se buscaría avanzar en un proceso de reforma integral que abarcaría al conjunto del sistema educativo, impulsando un proceso de "racionalización" y “eficientización”, también aplicado al conjunto de la economía. Prácticamente la totalidad de los niveles educativos serían transformados: la educación básica, el nivel medio, la formación docente y la universidad. Se buscaba dejar atrás, así, la ausencia de una ley orgánica para el conjunto del sistema. ${ }^{4} \mathrm{El}$ primer paso en la reforma de la educación básica se daría en 1968. A través de la Resolución Ministerial No 994 se establecería una nueva estructura para el nivel primario y el medio. La educación primaria era dividida ahora en tres ciclos y pasaba de siete a cinco años de duración. A su vez, se creaba la "escuela intermedia", un nivel de cuatro años que mediaba entre la primaria y la secundaria. En el nuevo esquema, el nivel medio "perdía" dos años (al igual que la primaria), pasando de cinco a tres años de

\footnotetext{
${ }^{4}$ Para ampliar, véase: De Luca, R. (2006). "La reforma educativa de Onganía. El tercer momento de una estrategia". Razón y Revolución, núm. 15, pp. 165-182; De Luca, R. y Alvarez Prieto, N. (2013). "La sanción de la Ley Orgánica de las Universidades en la Argentina bajo la dictadura de Onganía y la intervención de los distintos organismos nacionales e internacionales en el diseño de las transformaciones". Perfiles Educativos, vol. 35, núm. 139, pp. 110-126.
} 
duración. Sin embargo, la obligatoriedad escolar se incrementaba de siete a nueve años al incluirse la escuela intermedia. Los "reformadores" consideraban que el tiempo obligatorio de escolarización resultaba insuficiente para crear los recursos humanos necesarios para el desarrollo y la modernización del país. Su ampliación, entonces, buscaba “adecuar" el proceso educativo a las tendencias mundiales imperantes que bregaban por el aumento de los años de escolarización. Otra novedad de la reforma era la apertura de distintas formas de acceder al sistema educativo. El nuevo esquema permitía el ingreso aún cuando el estudiante no hubiera cursado la etapa previa. Bastaba con acreditar un nivel de conocimiento y aptitudes suficientes para el ciclo.

¿Qué sucedía con el currículum? La reforma incorporaba en él, además de los contenidos, la totalidad de actividades desarrolladas por los alumnos en el espacio educativo. En relación a los primeros, a partir de ese momento se establecerían diferentes niveles operativos, dando lugar a tres tipos de contenidos: comunes, optativos y libres. Los "comunes" serían dictados en todas las escuelas del país. Los "optativos" eran aquellos que podían variar en cada una de las provincias, zonas o establecimientos. De esa forma, se aseguraría la suficiente flexibilidad en el currículum para que la educación se adaptara a las diversas necesidades regionales. Por último, las actividades libres se programarían "de acuerdo a las necesidades de la comunidad y de los padres de familia". Como vemos, los diseños curriculares contendrían una fuerte impronta regional. Cabe destacar que esta pauta comenzó a ser implementada parcialmente en el currículum en paralelo con una tendencia abierta hacia mediados de la década del cincuenta, vinculada a los procesos de descentralización administrativa. ${ }^{5}$ Desde la promoción en 1959 del Anteproyecto de Programa para la Educación Primaria (y su experimentación en 1961) y, posteriormente, la sanción de los Programas para Escuela de Provincia, en 1964, el currículum contemplaba diversas formas de regionalización. Se ubicaban en sintonía con las primeras manifestaciones de descentralización administrativa del sistema educativo sugeridas en 1956 y ensayadas por primera vez en 1961 como procesos de "transferencias" de escuelas de la Nación a la órbita provincial.

No era éste el único elemento que la reforma educativa del '68 retomaba de las propuestas anteriores. La centralidad que se le otorgaba al niño en el proceso de enseñanzaaprendizaje era un fenómeno ya presente en cambios curriculares previos, encarados durante

\footnotetext{
${ }^{5} \mathrm{La}$ "descentralización" administrativa supuso el traspaso de los servicios educativos desde la égida nacional hacia las provincias.
} 
los gobiernos de Frondizi e Illía. En ese sentido, ya no sería una pauta fija y general la que determinaría los progresos educativos sino el avance individual de cada estudiante. Lo nuevo de esta reforma sería la aplicación de este enfoque no sólo al currículum sino también a las pautas de evaluación y medición de resultados. Además, se introducían tiempos curriculares de personalización de la enseñanza, tanto para los alumnos más rezagados como para los más avanzados. En relación a este punto, al analizarse los documentos escolares de la época, aparecen una serie de cuestiones llamativas. Puede observarse que este seguimiento individualizado ya estaba instalado en forma previa, de manera que la reforma venía a reafirmar y extender concepciones anteriores. En los libros de actas de 1968 y 1969, conservados en el archivo histórico de la escuela "Mariano Acosta", se encuentra registrado el "concepto definitivo" de los alumnos de $4^{\circ}$ y $5^{\circ}$ año que un tribunal calificador, presidido por el Vicedirector, realizaba dos veces al año (en junio y octubre). Dicho concepto se formulaba en base a las calificaciones obtenidas en cada asignatura, la cantidad de inasistencias y las amonestaciones recibidas. En el caso de algunos alumnos se realizaban, además, una serie de observaciones puntuales. Entre ellas, se destacaban: "poca dedicación”, "falta de concentración", "falta de responsabilidad" o de "atención”, “dificultades de integración”, personalidad "inmadura", etc. Continuamente, se ponían en cuestión aspectos vinculados a los aprendizajes curriculares junto con otros de tipo conductual y disciplinario. El caso más recurrente era el de calificar a los alumnos como "flojos", categoría que refería tanto a una supuesta falta de predisposición o de "condiciones" para el estudio como a los magros resultados obtenidos en las distintas asignaturas. Incluso, en algunos casos el mal concepto era debido a la conducta del alumno y no ya por su rendimiento escolar. También se realizaban proyecciones vinculadas a la consideración que se tuviera sobre las "condiciones." o "aptitudes" de los alumnos para mejorar. En un caso, por ejemplo, se llegaba a caracterizar a un alumno como "irrecuperable". También aspectos tales como la higiene, el aseo, la vestimenta y la sexualidad eran controlados y evaluados por el cuerpo docente. Al respecto, se registraban una serie de valoraciones tales como: "su presencia es algo desagradable por su falta de pulcritud", "temperamento amanerado" o "raro", etc.

Como puede observarse, existía una fuerte impronta disciplinaria en las prácticas evaluativas que, si bien no era nueva, se profundizaría durante el régimen dictatorial. Ésta sería una de las consecuencias de la "individualización" de la enseñanza. En el caso de la escuela analizada, estas prácticas serían reforzadas a través de la labor del gabinete psicopedagógico, creado en 1969. Dicho gabinete poseía un legajo por alumno en el que 
figuraban, entre otras cuestiones, su "nivel mental y cultural", su grado de "adaptación social", sus "intereses escolares y extraescolares", etc. En el mismo sentido operaba el régimen de tutorías, a cargo del gabinete, orientado a encauzar rendimientos y conductas. Además de afianzar el control del alumnado, tanto el gabinete como los docentes consejeros debían orientarlos en los primeros años de tránsito de la escuela primaria a la secundaria.

En relación al sistema de evaluación curricular, a partir de la reforma, la promoción sería automática dentro de cada uno de los ciclos, salvo que se detectaran serias deficiencias. Este cambio de paradigma debe entenderse a la luz de las preocupaciones de la época. Diversos estudios y diagnósticos sobre el sistema educativo argentino ponían sobre el tapete los elevados índices de deserción y repitencia escolar, especialmente en el pasaje de la escuela primaria a la media. En ese marco, la promoción automática resolvería el problema aunque de un modo elusivo, es decir, sin atacar la raíz del problema.

En ese contexto, otro de los propósitos de la reforma, en el caso del nivel medio, era introducir una mayor flexibilidad en las modalidades en pos de resolver otras de las dificultades señaladas por los estudios educativos: la rigidez de la educación secundaria (que dificultaba movimientos horizontales entre modalidades). En particular, la obligación a una temprana elección vocacional, difícil de revertir. Por ello, en los estudios preliminares sobre la reforma se sugería que los planes de estudios fueran polivalentes y diversificados. El nivel medio debía avanzar para convertirse en un sistema "politécnico". Esa proyección implicaba que todas las modalidades se fusionarían. Por otro lado, acorde con la tendencia a la regionalización del sistema, se establecía que cada región o unidad operativa podía proponer especialidades de acuerdo a las necesidades de su medio. Todas poseerían un núcleo común de contenidos, un área de especialización y otra de actividades libres. El 50\% del tiempo del plan de estudios se destinaría a los primeros, un 33,3\% a la especialización y el 16,6\% restante al desarrollo de las actividades libres. Al terminar el nivel, además del título secundario, se entregaría un certificado de capacitación profesional que acreditaría los contenidos optativos aprobados.

Otra de las novedades que traía consigo la reforma consistía en la introducción de orientación vocacional dentro de la educación básica. Ésta sería impartida a partir del tercer ciclo de la primaria hasta la finalización de la secundaria. De acuerdo a los reformadores, el objetivo era que la escuela garantizara la inserción de los jóvenes en la sociedad. En ese marco, el currículum pasaba a contener un área denominada "orientación", compuesta por tres rubros destinados a la personalidad, los estudios y la vocación. El área en cuestión abarcaba 
tanto aspectos conductuales como otros más técnicos asociados a la elección de una profesión u oficio.

Para los reformadores, la piedra angular del cambio era la introducción de la escuela intermedia. Se destacaba como una herramienta de transición que tornaría menos abrupto el pasaje entre el nivel elemental y el medio. En ese sentido, si la primaria se estructuraba en torno a la figura de un único docente y la secundaria en torno a diez u once, este nuevo ciclo contaría con cuatro o cinco profesores. El currículum también se organizaría en torno a cuatro o cinco áreas de conocimiento: ciencias sociales y lengua; ciencias naturales y matemáticas; expresión artística y deportiva y actividades práctico-económicas.

Como puede verse, la reforma contemplaba múltiples cambios en la configuración del espacio educativo: la estructura y administración del sistema, el trabajo docente, el currículum, las formas de evaluación, etc. Su implementación fue impulsada a través de un proyecto de Ley elevado al Poder Ejecutivo en marzo de 1969 (Ministerio de Cultura y Educación, 1969). El proyecto insistía en la necesidad de introducir conocimientos prácticoslaborales en la escuela primaria. Se consideraba que una verdadera formación integral no podía descuidar la adquisición de pericias prácticas para el desempeño en el mundo del trabajo. A su vez, tal propósito era concebido en forma articulada con la necesidad de regionalizar la enseñanza. De ese modo, formación para el trabajo y regionalismo iban de la mano. En cuanto al currículum, en continuidad con los procesos de reforma previos, el proyecto sentaba su rechazo al "enciclopedismo". En ese sentido, la escuela debía enseñar a estudiar y a pensar a través de la observación, la experimentación y el razonamiento.

Cabe destacar que todos estos cambios suponían un avance paralelo de la descentralización administrativa del sistema. Proceso que debía implicar no sólo a las provincias sino que, también, llegaría hasta el nivel de las unidades escolares. Desde la perspectiva de la reforma, la escuela debía tener posibilidades completas de gestión así como una flexibilidad suficiente para responder a sus necesidades particulares, en permanente cambio. Por ello, debían redefinirse el funcionamiento y el gobierno de la educación. En esa dirección, de acuerdo al artículo $13^{\circ}$ de la Ley, la Nación tendría como tareas la planificación de los servicios educativos, la determinación de sus ciclos y modalidades, la reglamentación de las titulaciones y el dictado de las normas básicas para el funcionamiento del sistema. También debía prestar asistencia técnica y “concurrir subsidiariamente a la financiación de los servicios educativos". Las provincias debían planificar, crear y supervisar los servicios educativos en su jurisdicción, ajustar la duración de cada nivel y ciclo, determinar objetivos 
particulares y evaluar resultados. Ahora bien, la Nación y las provincias no eran los únicos agentes en materia educativa. Se destacaba a la familia en su rol "primario y natural". También eran reconocidos los Municipios, las universidades, la Iglesia Católica, las sociedades y asociaciones con personería jurídica y las "personas de existencia visible”. Estos últimos podían crear y sostener escuelas, formular programas y planes de estudio, seleccionar su planta docente, participar en el planeamiento educativo y en los presupuestos estatales para la educación, disciplinar la vida institucional y calificar y promover a su alumnado. En ese marco, la reforma le otorgaba potestad a cada escuela para la elaboración de su propio currículum. De ese modo, se proponía la fragmentación más absoluta del sistema.

Los reformadores suponían que el nuevo sistema brindaría una respuesta a las diferentes realidades de la población escolar, tanto en su desarrollo desigual a nivel evolutivo personal como en su contexto económico-social. Tales propósitos suponían una regulación mínima, dando lugar a un Estado Nacional "subsidiario" en materia educativa. De esa forma, los "cuerpos intermedios" de la sociedad cumplirían aquellas funciones reservadas en el pasado al Estado. Por supuesto, otra de las ventajas de este nuevo sistema sería que, de la mano de una mayor participación de la comunidad en la vida escolar, decrecerían los costos de sostenimiento del sistema. Como señalamos anteriormente, tal propósito se enmarcaba en un contexto más general de racionalización y eficientización de las diferentes dependencias a cargo del Estado y de los gastos asociados a ellas.

El proyecto de Ley fue aprobado y comenzaría a implementarse hacia 1970. Para llevar a cabo la reforma, se iniciaría una serie sucesiva de intervenciones. En primer lugar, el Decreto $N^{o} 1.301$ autorizaría al Ministerio de Cultura y Educación a modificar, establecer y aplicar planes de estudio con carácter experimental. Todos los planes serían provisionales hasta tanto fueran autorizados por el Poder Ejecutivo de la Nación. En el mes de mayo, la $I V$ Reunión Nacional de Ministros de Educación suscribió la nueva estructura para el sistema educativo. Allí, la Nación y las provincias se comprometieron a elaborar, en conjunto, una serie de contenidos mínimos y comunes para los primeros doce años de la escolaridad, que se renovarían periódicamente. Se decidió una implementación gradual de la reforma, a través de "micro-experiencias" que permitirían corregir errores sobre la marcha, a partir de la experimentación concreta. El ensayo comenzó en algunos grados $-1^{\circ}, 3^{\circ}, 6^{\circ}$ y $7^{\circ}-$ de cinco escuelas de la Capital Federal, 4 estatales y una del sector privado. Estas micro-experiencias fueron controladas por un "grupo de conducción". Cabe señalar que algunos de los 
especialistas allí convocados también fueron partícipes o defensores de la reforma de los años $90 .^{6}$

Un año más tarde, la experiencia se amplió a Buenos Aires, Córdoba, Chaco, Entre Ríos, Formosa, Mendoza, San Luis, Santa Fe y Santiago del Estero. Los informes de la época detallaban que la ampliación de la experiencia afectaba a 71 escuelas dependientes de la Superintendencia Nacional de Educación Privada (SNEP), 121 de la Consejo Nacional de Educación (CNE) y 159 de la Administración Nacional de Educación Media y Superior (ANEMS), en el nivel elemental. En el caso del nivel intermedio, la cobertura alcanzaba a 35 escuelas de la SNEP, 56 de la CNE y 163 de la ANEMS (Ministerio de Cultura y Educación, 1971). La selección de escuelas no fue azarosa sino que se buscó que el menor número de establecimientos reflejara las situaciones más diversas.

Sin embargo, hacia 1971 la reforma comenzaría a desandarse. Los docentes habían comenzado, a fines de 1970, un ciclo de protestas en oposición a ella y a la que afectaba a su propia formación. Ante la amenaza de un paro de 72 horas anunciado para el 2 de junio, el día $1^{\mathrm{o}}$ se puso fin a la reforma a través de la Resolución Ministerial $N^{\mathrm{o}} 1.734$. No obstante, las siguientes intervenciones en materia de política educativa retomarían algunas de las marcas introducidas por ella. Como forma más acabada, algunos aspectos de los Contenidos Mínimos para el nivel primario promulgados por la última dictadura militar, entre 1976 y $1977 .{ }^{7}$ Para el nivel medio, el proceso encarado en el Programa de transformación de la enseñanza media, en 1988, bajo el gobierno democrático de Raúl Alfonsín. ${ }^{8}$

\section{B. La década del noventa: un momento de consolidación}

Algunas de las tendencias inauguradas en los '60 no tuvieron marcha atrás en el sistema educativo e, incluso, pueden constatarse en la actualidad. Entre ellas, se destacan la descentralización y la regionalización educativa. Los años '90, bajo el gobierno de Carlos Saúl Menem (1989-1999), serían un nuevo período de consolidación. En ese momento se

\footnotetext{
${ }^{6}$ Dentro del grupo se encontraban el subsecretario de la Oficina Sectorial de Desarrollo "Educación” (OSDE) -asesor Prof. Alfredo Van Gelderen-, su director -Norberto Fernández Lamarra- y, por el equipo técnico, Inés Aguerrondo.

${ }^{7}$ Ministerio de Cultura y Educación (1977). Objetivos pedagógicos del nivel primario y del nivel medio. Contenidos mínimos del nivel primario común. Buenos Aires: Nueva Serie Divulgación.

${ }^{8}$ Ministerio de Educación (1988). Programa de transformación de la enseñanza media. Proyecto Ciclo Básico General. Aplicación en un número reducido de establecimientos. Buenos Aires: MEJ; Ministerio de Educación (1988). Programa de transformación de la escuela media. Proyecto Unificación del ciclo básico común y del ciclo básico comercial diurno. Buenos Aires: MEJ.
} 
desarrolló un proceso de reforma orgánica y global. Todo el sistema educativo fue transformado, desde el nivel inicial hasta la universidad. Cambiarían estructuras, planes y programas de estudio, aspectos vinculados a la administración y gestión del sistema, las formas de evaluación y los regímenes disciplinarios, etc. En esos años, se retomaron inclusive algunos aspectos de la reforma de los '60 que habían quedado en el olvido: la escuela intermedia (ahora denominada "EGB3") y la promoción automática (antes oficial y ahora de hecho). La diferencia central entre un momento y otro residiría en el grado de consolidación alcanzado. Mientras la reforma proyectada por Onganía permaneció en ensayo poco tiempo, la de los '90 afectó a la mayor parte del sistema educativo y alcanzó su máximo desarrollo, afianzándose por espacio de trece años (hasta el año 2006, momento en el que se sanciona la Ley de Educación Nacional, No 26.206).

Si bien aquí se señalarán los puntos en común de ambos momentos de reforma, cabe destacar que la diferencia entre esos procesos remite a la etapa más general en la que se desarrollaron las transformaciones. Como vimos antes, la "Revolución Argentina" operó en un período de crisis hegemónica -crisis política, económica y social (Sartelli, 2011). El régimen político encabezado por Onganía intentó llevar a cabo una serie de transformaciones que buscaban cerrar esa crisis en marcha y resolverla a favor de los sectores más concentrados del capital. En materia educativa, su gestión sintetizó algunas tendencias que en forma incipiente se desarrollaban (regionalización, descentralización, eficientización del sistema) y las colocó en el interior de un proyecto de cambio más amplio. Sin embargo, la agudización de la crisis social luego del llamado "Cordobazo" puso un freno a esa experiencia. En un contexto en el cual fracciones de la clase obrera y de la pequeña burguesía desafiaban el orden instituido a través de la acción directa, no resulta casual que la oposición docente a la reforma fuera un obstáculo central.

\footnotetext{
${ }^{9}$ El 29 de mayo de 1969 una huelga general convocada por los sindicatos de la provincia argentina de Córdoba derivaría en una insurrección de masas, conocida como el "Cordobazo". Durante aquella jornada, se establecería un combate abierto entre las fuerzas armadas del Estado y las masas. Como resultado, el Ministro de Economía -Krieger Vasena- renunciaría a su cargo y la dictadura militar se vería fuertemente debilitada. De tal modo, en 1970 el presidente de facto, Juan Carlos Onganía, sería reemplazado por el militar Roberto Marcelo Levingston. El "Cordobazo" formó parte del comienzo de una tendencia a la acción insurreccional de las masas que se desarrollaba en las calles, por fuera de los canales institucionales -partidos y sindicatos. En ese contexto debe entenderse la sucesión de "azos" durante la década del setenta en nuestro país -"rosariazo", "correntinazo", "mendozazo", "viborazo", etc. En tanto cuestionamiento directo al Estado, todos ellos daban cuenta de los síntomas del agotamiento político del reformismo y advertían el inicio de un proceso de características revolucionarias. Para ampliar, véase: Balvé, B. (et. al.) (2005): Lucha de calles, lucha de clases (Córdoba 19711969), Ediciones ryr - CICSO, Buenos Aires.
} 
El golpe militar de 1976 lograría reconstruir la hegemonía burguesa a partir de la eliminación de la fuerza social revolucionaria (la alianza que cuestionaba el orden social capitalista instituido) y la articulación de los intereses centrales del conjunto de la burguesía argentina. En ese marco, desde la reapertura democrática de 1983 se observará el inicio de una etapa de relativa estabilidad política con la sucesión de gobiernos constitucionales por la vía electoral. ${ }^{10}$ En ese sentido, el contexto en el cual se desarrolló la reforma de los '90 resultó muy diferente al de la década del sesenta. Precisamente, el cierre de la crisis hegemónica a partir del golpe militar de 1976 permitió la consecución de una serie de tareas antaño requeridas. El proceso de concentración y centralización del capital operado en esos años agudizó las diferencias regionales de productividad. También, la fractura de la clase obrera a partir de su "derrota" política y la consolidación de una masa de población "sobrante" para las necesidades de valorización del capital que se expresaría en esos años fenoménicamente bajo la figura de los "desocupados". No extraña entonces que, a partir de esos años, la tendencia del sistema educativo a la descentralización administrativa y curricular lograra consolidarse.

Debe señalarse, asimismo, que las reformas de la década del noventa no fueron exclusivas de nuestro territorio. Fue el caso también de Brasil, especialmente bajo el gobierno de Fernando Henrique Cardozo (1995-2002). Al igual que en Argentina, las políticas educativas durante aquella etapa se caracterizarían allí por la adopción de mecanismos de flexibilización y diversificación de los sistemas de enseñanza y de las escuelas, la descentralización administrativa y financiera. Un rasgo acentuado del caso brasilero reside en el establecimiento de sociedades con el empresariado (Confederación Nacional de Trabajadores de la Educación, 2005). Proceso particularmente visible en la educación básica. En ese marco, las instituciones educativas públicas tuvieron que buscar en el mercado -por la vía de cobranza de tasas, trabajo voluntario y otras fuentes- los recursos necesarios para recomponer sus presupuestos. En cuanto a los contenidos de enseñanza, como veremos también para el caso argentino, se consolidó una base pragmatista y utilitarista, vinculada a las necesidades de los distintos nichos de acumulación del capital.

El primer paso en la transformación educativa argentina durante los noventa fue dado por la Ley $\mathrm{N}^{\mathrm{o}} 24.049$, de transferencia a las provincias de los servicios educativos, sancionada

\footnotetext{
${ }^{10}$ No obstante, ello no supuso un período exento de conflictividad social. En ese sentido, Alfonsín se vería obligado a acelerar el traspaso de la presidencia en el marco de una profunda crisis social originada en un contexto económico hiperinflacionario.
} 
en 1991. Ésta culminó el proceso de descentralización iniciado en la década del '50. ${ }^{11}$ A partir de entonces, ya no quedarían escuelas a cargo del Estado Nacional. Luego, en abril de 1993, se sancionaría la Ley Federal de Educación -LFE- No 24.195. ¿Qué cambios introducía en relación a la estructura del sistema? Al igual que en la reforma de los '60, la educación general básica pasaba a contar con nueve años de duración (en lugar de siete). Además, se organizaron tres ciclos en su interior: EGB1, EGB2 y EGB3. Luego, le seguía el trayecto denominado "polimodal" con una duración de tres años. Una novedad de esta reforma sería la obligatoriedad de la sala de 5 años en el nivel inicial.

La Ley establecía un sistema educativo "flexible", orientado a satisfacer las necesidades nacionales y la diversidad regional (art. $9^{\circ}$ ). En ese sentido, además de la descentralización educativa, la regionalización del currículum cobraría nuevo impulso. Al respecto, la ley establecía que la política educativa fortalecería la identidad nacional atendiendo las idiosincrasias locales, provinciales y regionales. Por su parte, las modalidades del nivel medio -“polimodal"- estarían determinadas por las demandas del campo laboral, las prioridades comunitarias, regionales y nacionales (art. $66^{\circ}$ ). Todo ello resultaba posible en la medida en que la descentralización había sido extendida a la totalidad del sistema educativo. En ese sentido, la LFE le otorgaba a cada jurisdicción potestad plena para planificar, organizar y administrar el sistema educativo en su territorio (art. $59^{\circ}$ ), en el marco de los lineamientos generales fijados por la Nación. A su vez, se avanzaba un paso más en la búsqueda de participación de otros actores sociales en la vida educativa. Para ello, tanto el Estado nacional como el provincial garantizarían el acceso a la educación con la participación de la familia, la comunidad, sus organizaciones y la iniciativa privada. Las acciones educativas eran consideradas responsabilidad de la familia, como agente natural y primario, del Estado, la Iglesia Católica, las demás confesiones religiosas (reconocidas oficialmente) y las organizaciones sociales.

En cuanto a los contenidos, el Ministerio de Cultura y Educación establecería, en acuerdo con el Consejo Federal, una serie de objetivos y "contenidos básicos comunes" CBC. De esa forma, al existir contenidos comunes a todas las escuelas, se facilitaría la movilidad horizontal y vertical de los alumnos. Sin embargo, también se dejaría abierto un importante espacio curricular para la incorporación de contenidos vinculados a los requerimientos provinciales, municipales, comunitarios y escolares. En ese sentido, cada

\footnotetext{
${ }^{11}$ Para la reconstrucción del proceso en términos estadísticos puede consultarse: De Luca, R. (2008). Brutos y baratos. Descentralización y privatización en la educación argentina (1955-2001). Buenos Aires: Ediciones ryr.
} 
jurisdicción e institución aprobarían sus propios currículos. En relación con este punto, al igual que en los '60, la reforma buscaría estrechar los lazos con el mundo productivo. En ese sentido, en su artículo $5^{\circ}$, la LFE establecía que la política educativa valorizaría el trabajo como eje vertebrador del proceso social y educativo. Por ello, los educandos tenían derecho a recibir orientación vocacional, académica, profesional y ocupacional. Orientación que posibilitaría su inserción en el mundo laboral o la prosecución de los estudios en el nivel superior. Por otro lado, se abría la posibilidad de crear ofertas educativas de menor duración y con preparación ocupacional específica para quienes hubieran finalizado la EGB. En este caso, se introducía una cláusula que permitía acceder a los distintos niveles sin haber cumplido los anteriores (Art. $12^{\circ}$ ). Bastaba con que un jurado acreditara las aptitudes y conocimientos requeridos.

Atenta a las necesidades del mundo productivo, la LFE introducía en el nivel polimodal un régimen de "alternancia" entre la institución escolar y las empresas. En ese marco, las organizaciones empresarias y sindicales asumirían un compromiso en el proceso de formación, aportando "iniciativas pedagógicas", espacios adecuados y acceso a la tecnología del mundo del trabajo y la producción. Este régimen tenía antecedentes previos, tales como el "sistema dual" implementado durante la última dictadura militar. ${ }^{12}$

En diciembre de 1993, el Consejo Federal aprobó las orientaciones para acordar los CBC (Resolución No 33/93), entendiéndolos como un “conjunto de saberes relevantes". Constituirían el primer nivel de definición curricular: el fijado por la Nación. Ellos serían luego procesados y resignificados localmente, en interacción permanente con elementos "extracurriculares". En ese sentido, eran pensados como una herramienta estratégica para organizar un sistema educativo descentralizado e "integrado" a la vez. De acuerdo a la Resolución del Consejo, los CBC se orientarían a la formación de "competencias" en relación al desarrollo ético, socio-político-comunitario, del conocimiento científico tecnológico y de la expresión y la comunicación. Dichas competencias pondrían en juego capacidades intelectuales, prácticas y sociales. Ahora bien, ¿cuáles serían los criterios para establecer los contenidos comunes? En primer lugar, serían "significativos" socialmente. De acuerdo al consejo, tal orientación hacía referencia a "la importancia de los CBC para contribuir a mejorar la calidad de vida del conjunto de la población" (III.1). En segundo término, se

\footnotetext{
${ }^{12}$ El "sistema dual", creado en 1979, conformaba un nuevo circuito dentro de la modalidad técnica de educación. El método de trabajo consistía en prácticas laborales concretas como mecanismo de formación de los educandos.
} 
consideraría su "extensión y profundidad", reemplazando el afán de abarcarlo todo por el de su "potencia educadora". Este rechazo a la extensión de los contenidos en pos de una teórica mayor profundidad, característico también de la reforma de los sesenta, se justificaba ahora bajo nuevos términos. La rapidez de la evolución de los conocimientos y de los procedimientos técnicos habría transformado la "ilusoria pretensión de 'enseñar todo a todos' propia del enciclopedismo" (III.2). En ese sentido, resultaba necesario distinguir entre aquellos contenidos pasibles de aprenderse en la escuela de aquellos que un mundo "altamente tecnificado" pondrían a disposición de los alumnos por fuera de ella. Vinculado a ello, otro parámetro para la elaboración de los $\mathrm{CBC}$ sería el compromiso sobre su permanente revisión y actualización. También, debía considerarse la "integración y totalización” de los contenidos diseñados. Se promovería la articulación entre la teoría y la práctica, la transferencia de generalizaciones a contextos concretos y la consideración de situaciones reales. Así, se enfatizaba la necesidad de una educación vinculada a la práctica y a la realidad del medio. La "regionalización" suponía, además, la "apertura" de los contenidos a las diferentes realidades y concepciones existentes en el país. Se tomarían en consideración las identidades personales, familiares, locales y regionales. Otro aspecto a considerar era la articulación horizontal y vertical de los contenidos. La primera hacía referencia a la conexión y coherencia al interior de cada campo o área. La segunda suponía tomar en cuenta la lógica interna de las distintas disciplinas, la evolución personal de los alumnos así como la movilidad de la población escolar.

Unos meses más tarde, el 5 de julio de 1994, el Consejo Federal aprobó los “Criterios para la Planificación de Diseños Curriculares en las Provincias y la Municipalidad de la Ciudad de Buenos Aires" (Resolución No 37/94). Allí se estableció que los diseños curriculares tendrían bases comunes, igual carga horaria mínima y una serie de campos del conocimiento que debían contemplar ineludiblemente (Lengua, Matemática, Ciencias Naturales, Ciencias Sociales y Tecnología, área Estético Expresiva y Físico-Deportiva). Los CBC para los dos primeros niveles de la EGB, serían determinados por ciclo y no por grado para facilitar su integración de acuerdo con las peculiaridades de las provincias, "privilegiando el criterio según el cual para lograr equidad en contextos diferentes es conveniente adoptar estrategias, entre ellas la secuenciación, también diferentes" (III.2c). En el caso del tercer ciclo de la EGB, los contenidos serían presentados por disciplina -si bien éstas serían agrupadas de la misma forma que en los dos primeros ciclos- y por año (III, $3 b$ ). 
Los CBC serían finalmente aprobados en noviembre de 1994 (Resolución Nº 39/94) y modificados en julio del año siguiente (Resolución $N^{o}$ 40/95). Se presentaban en capítulos organizados a partir de su pertenencia a determinados campos científicos o culturales (Lengua, Matemática, Ciencias Naturales, Ciencias Sociales, Tecnología, Educación Artística, Educación Física y Formación Ética y Ciudadana). Dentro de cada capítulo, los contenidos eran divididos en bloques correspondientes a los conceptos propios de cada disciplina, los procedimientos y las actitudes y valores vinculados con esos conocimientos. Vale destacar que una parte importante del currículum se orientaba a pautar aspectos actitudinales y de formación de valores. Por otro lado, la pauta regionalizadora era reforzada al establecerse que, a lo largo de la planificación curricular, las provincias podrían reorganizar los $\mathrm{CBC}$ de “múltiples maneras". En ese sentido, la estructura establecida por el Consejo no prescribía una organización específica para la enseñanza de los contenidos consignados.

¿Qué sucedía con la evaluación de los aprendizajes? No sería sino hasta noviembre de 1999 que el Consejo Federal aprobaría un acuerdo "marco" sobre evaluación, acreditación y promoción (Resolución $\mathrm{N}^{\mathrm{o}}$ 117). Allí, la evaluación era considerada como un proceso “complejo y continuo de valoración de las situaciones pedagógicas, de sus resultados y de los contextos y condiciones en que éstas se producen" (I. "Marco General"). En ese sentido, la evaluación iría más allá de los procesos y logros de aprendizaje referidos a los contenidos conceptuales, procedimentales y actitudinales. Se proponía una nueva "cultura evaluativa" que calificaría los logros cualitativamente en lugar de hacerlo en forma cuantitativa. Para ello, debía tener en cuenta todo el período evaluado, por lo que las calificaciones obtenidas en las primeras etapas del año no tendrían un peso definitorio en la calificación final. Por otra parte, debían instrumentarse instancias complementarias, de carácter compensatorio, orientadas a garantizar a todos los alumnos oportunidades para el logro de los aprendizajes previstos. Por ello, la evaluación debía atender los “distintos estilos y ritmos de aprendizaje". Los contenidos actitudinales también debían ser contemplados en el diseño de los procesos evaluativos. No obstante, éstos no podrían ser considerados en sí mismos como parámetro para la acreditación y promoción dado su carácter más bien subjetivo. Finalmente, la resolución indicaba la necesidad de dar participación en el proceso evaluativo a todos los actores de las situaciones pedagógicas, incluyendo a los alumnos. En este punto, se observan elementos de contacto y de ruptura en los dos momentos de reforma aquí analizados. Si bien ambos compartían un enfoque orientado a evaluar rendimientos académicos y conductas, en los noventa comienzan a aparecer otros actores como protagonistas del proceso evaluativo. 
Si bien excede los objetivos establecidos en este artículo, cabe destacar que la reforma se tradujo en la implementación de nuevos diseños curriculares por parte de las provincias y la emergencia de nuevos libros de texto. Tanto en uno como en otros, se profundizó la regionalización del currículum, proceso que -junto a la descentralización administrativa y financiera- agudizó la fragmentación y segmentación del sistema. Este aspecto se constató en diversos indicadores. No sólo en el currículum escolar sino también en los rendimientos desiguales del sistema, evidenciados en las distintas evaluaciones de las que el país fue partícipe desde fines de los noventa a la actualidad.

En suma, ¿qué se puede decir, a modo de balance, sobre los procesos de reforma aquí estudiados?

\section{Conclusiones provisorias}

La reforma educativa llevada a cabo por la dictadura encabezada por Onganía se colocaba en sintonía con una serie de tendencias que se venían desarrollando desde 1955, tales como la descentralización del sistema y la regionalización curricular. Sin embargo, su carácter integral le imprimiría un nuevo dinamismo y una nueva extensión a todas esas tendencias previas, buscando ahora su consolidación. Como se ha señalado antes, si bien la reforma fue desarticulada prontamente, sus huellas permanecerían en los procesos de transformación educativa posteriores. Finalmente, la reforma de los años noventa consolidaría, definitivamente, aquellas tendencias ya presentes en los años sesenta. A partir de ese momento, la descentralización abarcaría al conjunto del sistema, la regionalización del currículum sería generalizada, la orientación de una educación para el trabajo se traduciría en un régimen de "alternancia” entre la escuela y la fábrica, etc.

El análisis comparativo realizado en este trabajo pone en cuestión el carácter improvisado o disruptivo que los estudios educativos le otorgaron a la reforma de la década del noventa. Por otro lado, a modo de hipótesis, podría pensarse que algunos de los elementos característicos de ambos momentos de reforma -contenidos "mínimos", promoción automática, apuesta a lo local en detrimento de la totalidad, etc.- podrían estar dando cuenta de un proceso de "degradación educativa". Degradación entendida como un lento pero sostenido proceso de deterioro de los saberes y conocimientos que se ponen en juego en el sistema educativo. Su estudio formará parte de las siguientes etapas de la presente investigación. 


\section{Bibliografía}

ALBERGUCCI, R. (1996): La aplicación de la Ley Federal, Buenos Aires, Alianza.

ANDERSON, P. (1981): Las antinomias de Antonio Gramsci, Barcelona, Fontamara.

BALVÉ, B. (et. al.) (2005): Lucha de calles, lucha de clases (Córdoba 1971-1969), Ediciones ryr CICSO, Buenos Aires.

BATIUK, V. (2006): Derechos y justicia. Para vos, para mí y para todos, Buenos Aires, CIPPEC.

BRASLAVSKY, C. et. al. (2001): La educación secundaria ¿cambio o inmutabilidad? Análisis y debate de procesos europeos y latinoamericanos, Buenos Aires, Santillana.

CONFEDERACIÓN NACIONAL DE TRABAJADORES DE LA EDUCACIÓN (2005): "Informe Brasil", en CTERA et. al.: Las reformas educativas en los países del Cono Sur, Buenos Aires CLACSO.

CORAGGIO, J. (1997), La educación según el Banco Mundial, Buenos Aires, Miño y Dávila. DAVINI, M. (1998): El currículum de formación del magisterio en Argentina, Buenos Aires, ACA.

DE LUCA, R. (2006): "La reforma educativa de Onganía. El tercer momento de una estrategia", en Revista Razón y Revolución, núm. 15, Buenos Aires, pp. 165-182.

DE LUCA, R. (2008): Brutos y baratos. Descentralización y privatización en la educación argentina (1955-2001), Buenos Aires, Ediciones ryr.

DE LUCA, R. Y ALVAREZ PRIETO, N. (2013): "La sanción de la Ley Orgánica de las Universidades en la Argentina bajo la dictadura de Onganía y la intervención de los distintos organismos nacionales e internacionales en el diseño de las transformaciones", en Perfiles Educativos, vol. 35, núm. 139, México, pp. 110-126.

DE LUCA, R. Y SOUTHWELL, M. (2009): "Descentralización política y formación docente: el CONADE como intervención política", en Revista de la Escuela de Ciencias de la Educación de la Universidad Nacional de Rosario, núm. 3, Año IV, Rosario, Laborde, pp. 375-389.

ECHENIQUE, M. (2003): La propuesta educativa neoliberal. Argentina (1980-2000), Buenos Aires, Homosapiens.

FELDMAN, D. y PALAMIDESSI, M. (1994): "Viejos y nuevos planes", en Propuesta Educativa, Año 5, núm. 11, Buenos Aires, pp. 69-73.

GAMARNIK, R. (1996): La Revolución Argentina. Proyecto político y reforma educativa, Buenos Aires, Facultad de Filosofía y Letras.

GRINBERG, S. (2005): El mundo del trabajo en la escuela: la producción de significados en los campos curriculares, Buenos Aires, Jorge Baudino Ediciones.

MINISTERIO DE CULTURA Y EDUCACIÓN (1969): Proyecto de “Ley de Educación” del Ministro Guillermo A. Borda y del secretario de estado José Mariano Astigueta, Buenos Aires, MCE. 
MINISTERIO DE CULTURA Y EDUCACIÓN (1971): Descripción de los proyectos de experimentación de la reforma educativa, Buenos Aires, MCE.

MINISTERIO DE CULTURA Y EDUCACIÓN (1977): Objetivos pedagógicos del nivel primario y del nivel medio. Contenidos mínimos del nivel primario común, Buenos Aires, Nueva Serie Divulgación.

MINISTERIO DE EDUCACIÓN (1988): Programa de transformación de la enseñanza media. Proyecto Ciclo Básico General. Aplicación en un número reducido de establecimientos, Buenos Aires, ME.

MINISTERIO DE EDUCACIÓN (1988): Programa de transformación de la escuela media. Proyecto Unificación del ciclo básico común y del ciclo básico comercial diurno, Buenos Aires, ME.

MIRANDA, E. y LAMFRI, N. (2001): "Tensiones y conflictos en procesos recientes de transformación de la educación Argentina: contextos, políticas y actores", en Martinic, S. y Pardo, M. (eds.): Economía política de las reformas educativas en América Latina, Chile, CIDE.

PALAMIDESSI, M. (2009): "El currículum para la escuela primaria argentina: continuidades y cambios a lo largo de un siglo", en Terigi, F., Diez miradas sobre la escuela primaria, Buenos Aires, Siglo XXI.

PAVIGLIANITTI, N. et al. (1989): Diagnóstico de la administración central de la educación, Buenos Aires, Ministerio de Educación y Justicia.

PUIGGRÓS, A. (2003): Dictaduras y utopías en la historia reciente de la educación argentina (1955-1983), Colección Historia de la Educación en la Argentina, vol. VIII, Buenos Aires, Galerna.

PUIGGRÓS, A. (2003b). Qué pasó en la educación argentina. Breve historia desde la conquista hasta el presente, Buenos Aires, Galerna.

SANGUINETTI, H. (2006): La educación argentina en un laberinto, Buenos Aires, FCE.

SARTELLI, E. (1996): “Celeste, blanco y rojo. Democracia, nacionalismo y clase obrera en la crisis hegemónica”, Revista Razón y Revolución. Buenos Aires: Ediciones ryr, n. 2.

SARTELLI, E. (2006): La plaza es nuestra. El argentinazo a la luz de la lucha de la clase obrera argentina del siglo XX, Buenos Aires, Ediciones ryr.

SARTELLI, E. (2011): La crisis orgánica de la sociedad argentina, Buenos Aires, Facultad de Filosofía y Letras.

TIRAMONTI, G. (2010): La trama de la desigualdad educativa. Mutaciones recientes en la escuela media, Buenos Aires, Manantial.

VIOR, S. (1999): Estado y educación en las provincias, Buenos Aires, Miño y Dávila.

ZIEGLER, S. (2001): "De las políticas curriculares a las resignificaciones de los docentes. Un análisis de la reforma de los años noventa en la provincia de Buenos Aires a partir de la recepción de documentos curriculares por parte de los docentes", tesis de Maestría en Ciencias Sociales, Buenos Aires, Flacso. 